graph is not only an excellent introduction to the subject of radioactive isotope dilution analysis but also a valuable laboratory guide for those who wish to make use of tho technique. There is a list of 25 references from which additional information can be obtained.

\section{Solid-state Physics}

THE Bulletin de la Société Belge de Physique is published by the Bolgian Physical Society and records the proceedings of meetings on special topics organized by the Society. Regular members of the Society receive the Bulletin, but non-members can subscribe at 400 Belgian francs per sories of six issues. The number of issues per annum ranges from four to six. The March 1964 issue (Series 4, No. 1) contains the proceedings of the armual meeting on "Solid-state Physics", held in Brussels on Octobor 11, 1963. There were 21 contributions and these, somo in abstract or summary form, are printed in English in the issue.

\section{Albright Magazine}

THE ingredients of a successful house journal of the type and quality nowadays sponsored by leading industrial concerns in Britain and overseas would appear to be attractive format and presentation, a nice balance between articles of technical and general interest and those concerned with the social activities of employees, high-quality illustration (sensitive blending of black and white and colour), and what may be best described as 'oxtra-mural' appeal. Circulation of magazines of this type, in many long-established and successful ventures, goes far boyond the patronago of the employees for whom they were primarily instigated, and deservedly so. The merits of these periodicals are that by means of informative articles, lavishly illustrated by photographs and diagrams, and written by administrative and technical experts, often outside the organization concerned, business, technology, general knowledge, and the social humanities are happily blended to the advantage of all concerned. As a tangible means of promoting esprit de corps and good staff relationships, such projocts can scarcely be bettered. A comparative newcomer to the library of British house journals is the Albright Magazine, a bi-monthly periodical published by the well-known Albright and Wilson group of companies with a wide field of chemical and allied interests. The first number appeared in February 1964, to be followed by the April, June and, to date, August issues. A survey of these four issues proclaims at once that a high standard of production was initially aimed at, and certainly achieved, and that it persists. This journal has originality plus all the ingredients mentioned here. As it appears to be the policy of the editorial board not to publish regular editorials, the first issue, likewise the second, was not introduced from the 'chair'; it was as though the Magazine just happened, leaving the reader to judge its merits. However, in the June issue, the Editor relents and gives the reader a glimpse of the policy behind this project, particularly information on how the first two numbers had been received. Generally, the reception of this publication has been extremely good, including comments from an independent critic well accustomed to reviewing house journals. Two points in presentation, however, have been raised: the use of the + sign in place of an ampersand connecting Albright and Wilson, and the 'readability' of the sans serif type so far used in the text. The writer of this note frankly considers the former rather ugly and incongruous; the matter of type, on which the Editor asks for comments, is largoly a matter of opinion; at first sight it appears rather formal, like some government specifications, and not so easy to the eyes as many house journals. Apart from these queries, it will be surprising if in the next National House Journal Competition (one has already been held for 1964) the Albright Magazine does not receive an award for morit, which it undoubtedly deserves.

\section{Mechanizing Library Services}

THE June-July issue of Science Information Notes (6, No. $3 ; 1964)$, issued by the National Science Foundation, records the commencement of an investigation, under an arrangement by the Council on Library Resources, to demonstrate that bibliographic information, suitably punched into a perforated paper-tape record by a tapeproducing typewriter, can be reproduced in any form required for the records used in library operations. The purpose is to lay the basis for seeking general agreement on standards in the conversion of such information to machine-readable form. The National Science Foundation is itself supporting the American Institute of Physics in a programme directed towards improving the communication of sciertific information. This will enable the Institute to continue its work on creating an adequate reference retrieval system for physicists, its collection of information from authors using the property-objectmethod scheme of analysis, and its investigation of the relations betwoen cited and citing physics papers, including an investigation of the reasons why articles are cited. An experimental system which can uso the data already collected will also be tested. Research is continuing at the Massachusetts Institute of Technology on the development of a realistic test environment for evaluating ideas and systems components capable of making the flow of scientific information more effective. The National Aeronautics and Space Administration has established an unusual search tape system which provides up-to-date comprehensive search capabilitics at individual research contres of the Administration's entire collection of reports.

\section{The Sarawak Museum}

The latest issue of the Sarawak Museum Journal (11, Nos. 21-22 (New Series); July-December 1963) maintains the essential regional character of this publication. Mrs. Barbara Harrisson records some interesting experiments in educating orphan young orang-utans for normal life in the jungle, and the editor, Mr. Tom Harrisson, has several papers on local natural history. Additional information regarding the animal bones found in Niah Cave are given by Lord Medway and the Earl of Cranbrook. In all, there is a total of 31 interesting and wellillustrated papers.

\section{South Australian Museum}

THE report of the South Australian Museum for the year ended June 30, 1963 (Pp. $14+1$ plate. Adelaide: Government Printer, 1964), is the first issued under the directorship of Dr. W. P. Crowcroft, and records the continued anxiety regarding accommodation. The installation of a mezzanine floor in the Stirling Gallery provided an extra $1,500 \mathrm{ft}^{2}$ for storage. Several collecting projects were undertaken during the year, with the view of acquiring detailed field observations in support of material collected for research purposes, and the recording of the destruction of native habitats. Trips were thus undertaken to the Gulf of Carpentaria, the Simpson Desert, and Sturt's Stony Desert. Some of the records of this work are indicated in an impressive list of publications by the staff.

\section{Physics Conference, Gothenberg}

The twelfth General Physics Conference arranged by tho Swedish National Committee for Physics was held in the Chalmers Institute of Technology, Gothenberg, during June 4-7, 1963. The attendance of some 300 members, and particularly the large number of contributed papers, required the meetings to be held in three parallel sessions in adjacent lecture halls. One general lecture was given each day by an invited speaker. Prof. D. Amati (CERN) spoke on the present situation in the high-energy theory; Dr. J. J. Quinn (Radio Corporation of America) on the 